\title{
Coordination of Supply Chains with Competing Manufacturers considering Fairness Concerns
}

\author{
Jie Jian $\mathbb{D}^{1},{ }^{1}$ Yuyao Zhang $\mathbb{D},{ }^{1}$ Lin Jiang, ${ }^{1}$ and Jiafu Su $\mathbb{D}^{2}$ \\ ${ }^{1}$ School of Economics and Management, Chongqing University of Posts and Telecommunications, Chongqing, China \\ ${ }^{2}$ National Research Base of Intelligent Manufacturing Service, Chongqing Technology and Business University, Chongqing, China
}

Correspondence should be addressed to Jiafu Su; jiafu.su@hotmail.com

Received 4 September 2019; Revised 21 November 2019; Accepted 8 January 2020; Published 1 February 2020

Academic Editor: Guido Caldarelli

Copyright ( 2020 Jie Jian et al. This is an open access article distributed under the Creative Commons Attribution License, which permits unrestricted use, distribution, and reproduction in any medium, provided the original work is properly cited.

In this study, we examined the contract coordination between manufacturers with peer-induced and distributional fairness concerns. A revenue sharing contract was introduced to coordinate a competitive supply chain, in which the manufacturers have different fairness concerns based on centralized decision-making in terms of fairness neutrality. Then, we constructed two game models - the manufacturer's peer-induced fairness concern model and the manufacturer's distributional fairness concern model and analyzed the influence of a revenue sharing contract on the pricing decisions and profit distribution of a competitive supply chain considering fairness concerns. The results show that there is a revenue-sharing contract parameter in both the peer-induced and distributional fairness concerns of manufacturers, which can effectively realize Pareto improvements in a supply chain. Meanwhile, the retail and wholesale prices both decreased with the increase in the revenue-sharing ratio between retailers and manufacturers, and the profits of retailers decreased accordingly, but the overall utility of manufacturers and supply chains improved markedly. Moreover, the coordination condition is closely related to the level of fairness concerns of the manufacturers and the competition intensity between two manufacturers. The sharing contract designed in this study can not only effectively improve the utility of retailers and manufacturers but also enhance the total utility of the channel to ensure that node enterprises have long-term, stable, and cooperative relationships and to strengthen the overall competitiveness of the supply chain.

\section{Introduction}

There is a strong evidence that competition among manufacturers is very common. Similar to that between Pepsi and Coca-Cola, Airbus and Boeing, and so forth, cases of fierce competition emerge one after another. Upstream companies are increasingly pursuing channel fairness. The disequilibrium of profit distribution in supply chains exists universally. Kahneman et al., the winner of the Nobel Prize in Economics, first proposed the concept of fairness concerns under the hypothesis of limited rational parties; that is, economic people focus on the fairness of distribution results while seeking to maximize their own interests [1]. In the traditional supply chain model, decision-makers are usually assumed to be completely rational, meaning they act to maximize benefits as the decision-making goal. Under the tendency of fairness-concerned behavior, people take actions to punish each other at the expense of their own interests when they perceive unfairness, which has been confirmed by many empirical and experimental studies. In the existing literature, equity concerns are usually characterized by introducing profit differentials into the utility function, taking the profit of the other party as the reference point of one's own profit, where utility decreases when the profit of the other party is higher than that of one's own, and vice versa. For ease of exposition, we define a kind of behavior that a member cares about the fairness related to profit allocation as fairness concerns [2].

In practice, competing manufacturers also have equity concerns, such as Procter \& Gamble and Unilever, which supply Walmart with consumer goods. There is a level playing field between the two big manufacturers when there is intense competition between them and when one side shows signs of profit overtaking and the other side takes 
action to adjust its strategy, such as price competition. Similarly, the day-to-day aspect of Walmart's revenue raises fair-minded concerns for both manufacturers.

In recent years, due to the rapid development of the market economy and rise of the buyer's market, many products in various industries are faced with a situation of the supply exceeding the demand. The formation of small alliances to enhance the competitiveness of the entire channel, so as to coordinate and achieve win-win supply chain management for channel node enterprises, has become a topic of particular interest. The theory of supply chain coordination, first put forward by Pasternack in 1985, has effectively solved the core problem of supply chain management, namely, the problem of profit distribution [3]. The theory of supply chain coordination is to improve the efficiency of the entire supply chain by modifying transaction rules, such as contracts or protocols and the related variables that form the basis of contracts. This theory abandons the principle that each decision-making body in the traditional supply chain takes self-interest as its goal and, through the design of appropriate contract mechanisms, reshapes the supply chain enterprise cooperative relationship and strengthens the channel's market competitive power, thus improving interenterprise cooperative satisfaction. The existing classic contract mechanisms, such as sales rebates, revenue sharing, and cost sharing, use different coordination mechanisms to effectively solve the common supply chain phenomena of the marginal and bullwhip effects. The revenue-sharing contract is a common coordination mechanism based on a new income redistribution principle. The practice proves that its flexible distribution mechanism is especially suitable for a competitive supply chain with price-dependent demand.

Since Pasternack put forward the concept of supply chain coordination, more and more contract coordination mechanisms have been incorporated in supply chain management as part of the four basic supply chain contracts. There are two main types of revenue-sharing contracts. One involves the comparative study of revenue-sharing contracts and traditional wholesale price contracts. Another approach considers the application of revenue sharing contracts in a multiechelon supply chain.

Comparative studies have been done on revenue-sharing and traditional wholesale price contracts [4]. Yan and others constructed a simple two-level supply chain model with product quality and service guarantee. They discussed the profit distribution problem caused by the length of the warranty period for the node enterprises of the system and then designed a revenue-sharing contract coordinated with the warranty cost. The results showed that their contract solved the coordination problem which could not be realized by a traditional wholesale price contract [5]. Most studies focus on distributional fairness concerns in the wholesale price contract [6]. Luo and Tian considered the retailer's risk-averse preference and found that the common wholesale price contract cannot achieve the optimal benefit allocation of the supply chain under centralized decisionmaking. Therefore, a revenue-sharing contract was introduced to coordinate the double marginal effect of the supply chain, which improved the profit of both firms considered and improved the efficiency of the system [7]. Xu and others compared a wholesale price contract and a revenue-sharing contract in a multimanufacturer competition and cooperation game and analyzed the similarities and differences of the two systems' revenue distribution.

Research has also been carried out on improving and combining two revenue-sharing contracts [8]. Jane and others studied the influence of risk preference on a supply chain contract model, taking revenue sharing and wholesale price contracts as examples. They calculated the optimal decision of the supply chain system when a revenue-sharing contract was introduced and analyzed the effectiveness of the risk control tool CvaR for the contract model [9]. Liu and Shu found that a simple revenue-sharing contract or costsharing mechanism cannot coordinate a supply chain when considering service integrators' preference for fairness. The combination of the two can solve the problem of supply chain profit coordination, and a combination contract has coordination flexibility [10]. Zhao and Xu studied the supply chain coordination problem in the mixed channel of traditional retail and electronic direct selling. By designing an improved revenue-sharing strategy based on the wholesale price of manufacturers, the dual coordination of mixed channels could be realized and the channel conflict could be resolved [11]. Dan and Xu designed a traditional positive direction two-party revenue-sharing contract that also improved the reverse direction, which can achieve two-channel inventory coordination between enterprises [12]. Cao et al. studied the decision-making and coordination problem of a dual-channel supply chain considering customer preference and designed an improved revenue-sharing contract based on a simple price mechanism to realize dual-channel closedloop supply chain coordination [13]. On this basis, Zheng et al. further researched the coordination of a closed-loop supply chain with fairness concerns [14]. Sharma et al. investigated the fairness concerns of the channel members in a two-echelon supply chain composed of single supplier and single retailer, wherein the retailer procures products from the supplier using the option contract [15]. Wang studied the coordination of a two-echelon supply chain with bilateral information asymmetry and retailer risk aversion, and an effective compensation parameter for supply chain coordination was obtained [16].

Other studies have considered the application of threelevel revenue sharing contracts in multiechelon supply chains. For the first time, a revenue-sharing contract was introduced from a two-echelon supply chain to a threeechelon supply chain. It was found that the model could not only improve system efficiency by adjusting the contract parameters, it could also increase profits for all supply chain participants [17]. Hong and others constructed a complex three-echelon supply chain model consisting of manufacturers, distributors, and grey speculative markets. A compensation contract based on a revenue-sharing contract was designed to solve the coordination problem of a grey speculative market supply chain [18]. An improved gain/loss and risk-sharing portfolio contract was designed for a threeechelon supply chain with uncertain production and 
demand [19]. Zhang and Wang established a three-level and two-channel complex supply chain structure. After analyzing the system pricing decision, they used a combination contract of quantity elasticity and revenue sharing to realize supply chain profit coordination. In this study, a reasonable joint contract parameter was proposed which increases the profit of three-node enterprises and the whole supply chain [20].

To sum up, the aim of this paper was to find a contract mechanism that can coordinate a competitive supply chain with different fairness preferences and to explore the coordination principle of this mechanism. We established a supply chain model consisting of two competing manufacturers and one retailer, introduced the fairness concern theory of behavioral economics, considered the decisionmaking choice of supply chain members under the different manufacturers' fairness concerns, and compared and analyzed optimal decision-making and profits under three fairness concerns. Finally, we examined the fairness relationship of the manufacturers, the impact of the fairness concern level on the supply chain system, and the design of a revenue sharing contract to coordinate the supply chain system.

\section{Definitions and Assumptions}

In this study, we established a supply chain model consisting of one retailer and two competing manufacturers, which sell products through the same retailer. The relevant assumptions of the model are listed below:

(1) In order to simplify the calculation and to facilitate a focused analysis of the impact of equity concerns on the supply chain, it was assumed that both manufacturers $A$ and $B$ have the same production costs $C_{m}$ for their products, given that they produce only one product which are alternatives and they supply products to the same retailer at the wholesale price $W_{i}(i=1,2, j=3-i)$. The retailer sells the product to the consumer at the retail price $P_{i}(i=$ $1,2, j=3-i)$, assuming that the cost of selling the two products is the same $\left(C_{r}\right)$ [21].

(2) The consumer market satisfies the Bertrand model [6], and the demand function is $q_{i}=Q_{o}-P_{i}+\gamma P_{j}$, where the basic market demand is $Q_{0} ; P_{j}$ and $P_{i}$ are the retail prices of the two alternative products, respectively, $(i=1,2, j=3-i)$; and $\gamma$ represents the competition between the two products, $0<\gamma<1$.

(3) According to game theory, this paper establishes a manufacturer-led Stackelberg game model, and the dynamic game order of the supply chain is as follows $[22,23]$ : firstly, the two manufacturers determine their wholesale prices $W_{i}$ according to each other's prices. Then, the retailer reacts to determine the product's retail price $P_{i}$. Finally, the retailer sells products to consumers to meet market demand [24-26]. All members are rational and pursue own benefit maximization.
Based on the above assumption (Table 1), each decisionmaker rationally plays the game with the goal of pursuing his own profit maximization when all members in the supply chain system are fair and neutral [14]. At this point, the profit function for manufacturers, retailers, and the whole supply chain is as follows:

$$
\begin{aligned}
\pi_{i}= & \left(W_{i}-C_{m}\right)\left(Q_{o}-P_{i}+\gamma P_{j}\right), \quad i=1,2, j=3-i, \\
\pi_{r}= & \sum_{i=1}^{2}\left[\left(P_{i}-C_{r}-W_{i}\right)\left(Q_{o}-P_{i}+\gamma P_{j}\right)\right], \\
\pi= & \sum_{i=1}^{2}\left[\left(W_{i}-C_{m}\right)\left(Q_{o}-P_{i}+\gamma P_{j}\right)+\left(P_{i}-C_{r}-W_{i}\right)\right. \\
& \left.\cdot\left(Q_{o}-P_{i}+\gamma P_{j}\right)\right] .
\end{aligned}
$$

According to equation (2), the second derivative of the retailer's profit function with respect to retail price is a concave function since the system has a unique optimal retail price. In this case, the retailer's response function is derived from the first-order optimality condition:

$$
P_{i}=\frac{Q_{o}+(1-\gamma)\left(W_{i}+C_{r}\right)}{2(1-\gamma)} .
$$

When we put equation (4) into equation (1), the optimal wholesale price of the manufacturer is derived from the firstorder optimality condition:

$$
W_{i}^{*}=\frac{Q_{o}+(\gamma-1) C_{r}+C_{m}}{2-\gamma} .
$$

When we put equation (5) into equation (4), we get the optimal retail price of the retailer:

$$
P_{i}^{*}=\frac{(3-2 \gamma) Q_{o}+(1-\gamma)\left(C_{r}+C_{m}\right)}{2(1-\gamma)(2-\gamma)} .
$$

Then, when we put equations (5) and (6) into equations (1)-(3), we get the maximum profits for the manufacturer, retailer, and the whole supply chain:

$$
\begin{aligned}
& \pi_{i}^{*}=\frac{A^{2}}{2(2-\gamma)^{2}}, \\
& \pi_{r}^{*}=\frac{A^{2}}{2(1-\gamma)(2-\gamma)^{2}}, \\
& \pi^{*}=\frac{(3-2 \gamma) A^{2}}{2(1-\gamma)(2-\gamma)^{2}} .
\end{aligned}
$$

Among them, $A=Q_{o}+(\gamma-1)\left(C_{m}+C_{r}\right)$, and it is easy to verify $A>0$.

\section{Decentralized Decision-Making When Competing Manufacturers consider Fairness Concerns}

In order to study the influence of a decision-maker's equity concern on the supply chain system, we introduced the 
TABle 1: Parameters and their meanings.

\begin{tabular}{lc}
\hline Parameter & Meaning \\
\hline$Q_{0}$ & The basic market demand \\
$C_{m}$ & The production costs \\
$W_{i}$ & The wholesale price \\
$\lambda$ & The factor of fairness concern \\
$\gamma$ & The competition coefficient \\
$C_{r}$ & The cost of selling products \\
$P_{i}$ & The retail price \\
$\varphi$ & The revenue-sharing coefficient \\
\hline
\end{tabular}

equity concern coefficient $\lambda$ to express the decision-maker's equity concern degree to the reference point. Here, we assumed that both competing manufacturers have a preference for fairness concerns and use each other's profits as a point of reference to measure their own utility. This horizontal equity concern, also known as peer-induced equity concern, mostly exists between two agents engaged in the same activities: one side using the other as a decision-making criterion to judge fairness [27-32]. In this paper, the superscript " $\sim$ " is introduced to represent the decision-making of two competing manufacturers when they induce equity concerns on an equal footing. The utility function of the manufacturer was assumed to be as follows [15]:

$$
\widetilde{U}_{i}=\pi_{i}-\lambda\left(\pi_{j}-\pi_{i}\right), \quad i=1,2, j=3-i .
$$

Among them, $\lambda(\lambda \geq 0)$ is the fairness concern coefficient, and for the sake of comparison, it was assumed that the two manufacturers have the same degree of fairness concern; that is, the two manufacturers have the same fairness concern coefficient. $\lambda=0$ means that the two manufacturers are fair and neutral. $\lambda \longrightarrow+\infty$ means that the manufacturers are extremely concerned about fairness and are willing to pay a great cost to ensure fairness. Formula (10) shows that the utility function of the manufacturer decreases with the increase in the factor of fairness concern $\lambda$ when the competitor's profit is higher than his own, whereas when the competitor's profit is lower than his own, the utility function of the manufacturer increases with the increase in the factor of fairness concern $\lambda$.

\subsection{Decentralized Decision-Making When Competing Man-} ufacturers Are Equally Induced to Equity Concerns. The objective functions of the retailer and the whole supply chain are as follows when the manufacturer is equally induced to equity concerns:

$$
\begin{aligned}
& \widetilde{\pi}_{r}=\sum_{i=1}^{2}\left[\left(\widetilde{P}_{i}-C_{r}-\widetilde{W}_{i}\right)\left(Q_{o}-\widetilde{P}_{i}+\gamma \widetilde{P}_{j}\right)\right], \\
& \tilde{\pi}=\sum_{i=1}^{2}\left[\pi_{i}-\lambda\left(\pi_{j}-\pi_{i}\right)+\left(\widetilde{P}_{i}-C_{r}-\widetilde{W}_{i}\right)\left(Q_{o}-\widetilde{P}_{i}+\gamma \widetilde{P}_{j}\right)\right] .
\end{aligned}
$$

Like the game process in the previous section, the optimal wholesale price, retail price, market demand, and optimal profit of the manufacturer, retailer, and whole supply chain were obtained by using backward induction. The procedure is as follows.

According to equation (11), the second derivative of the retailer's profit function with respect to retail price is a concave function since the system has a unique optimal retail price. Assuming $\partial \widetilde{\pi}_{r} / \partial \widetilde{P}_{i}=0$, we get the retailer's response function:

$$
\widetilde{P}_{i}=\frac{Q_{o}+(1-\gamma)\left(W_{i}+C_{r}\right)}{2(1-\gamma)} .
$$

By substituting equation (13) for equation (10), the second derivative of the manufacturer's profit function with respect to wholesale price is a concave function, which shows that the supply chain system has a unique optimal wholesale price. Let $\partial \widetilde{U}_{i} / \partial \widetilde{W}_{i}=0$. From this, we get the optimal wholesale price of the manufacturers when fairness concerns are equivalently induced:

$$
\widetilde{W}_{i}^{*}=\frac{(1+\lambda) Q_{o}+(1+\lambda)(\gamma-1) C_{r}+(1+\lambda+\gamma \lambda) C_{m}}{\Delta_{1}} .
$$

When we put equation (14) into equation (13), we obtain the optimal retail price when the manufacturers induce fairness concerns equivalently:

$$
\widetilde{P}_{i}^{*}=\frac{(3+3 \lambda-2 \gamma-\gamma \lambda) Q_{o}+(1-\gamma)(1+\lambda+\gamma \lambda)\left(C_{r}+C_{m}\right)}{2 \Delta_{1}(1-\gamma)} .
$$

According to the above formula, the product demand can be obtained when the manufacturers induce fairness concerns equivalently:

$$
\widetilde{q}_{i}^{*}=\frac{(1+\gamma \lambda+\lambda)\left[Q_{o}+(\gamma-1)\left(C_{r}+C_{m}\right)\right]}{2 \Delta_{1}} .
$$

Then, we put equations (14) and (15) into equations (10) and (11), and we get the optimal utility of the manufacturer and the optimal profit of the retailer when the manufacturers induce fairness concerns equivalently:

$$
\begin{aligned}
& \tilde{U}_{i}^{*}=\frac{A^{2}(1+\lambda)(1+\gamma \lambda+\lambda)}{2 \Delta_{1}^{2}}, \\
& \tilde{\pi}_{r}^{*}=\frac{A^{2}(1+\gamma \lambda+\lambda)^{2}}{2(1-\gamma) \Delta_{1}^{2}} .
\end{aligned}
$$

We assumed that the two manufacturers are symmetrical, and $\widetilde{U}_{i}^{*}=\widetilde{\pi}_{i}^{*}$ obviously exists. Then, we get the total profit of the supply chain:

$$
\tilde{\pi}^{*}=\frac{A^{2}(3+3 \lambda-\gamma \lambda-2 \gamma)(1+\gamma \lambda+\lambda)}{2(1-\gamma) \Delta_{1}^{2}},
$$

where $\Delta_{1}=2(1+\lambda)-\gamma$. It is easy to verify $\Delta_{1}>0$ under the assumption of the fair concern coefficient $\lambda$ and the competition coefficient $\gamma$.

In summary, $\left(\widetilde{P}_{i}^{*}, \widetilde{W}_{i}^{*}\right)$ is the price strategy chosen by the retailer and manufacturer when competing manufacturers 
induce fairness concerns equivalently and $\widetilde{\pi}^{*}$ is the total profit of the supply chain in this case.

3.2. Decentralized Decision-Making When Manufacturers Distribute Fairness Concerns. As a decision-maker with a fairness preference, the manufacturer's reference point is not only limited to its competitors but may also include a downstream retailer in the same supply chain. Therefore, we assumed here that both competing manufacturers have a fairness concern preference and use the retailer's profit as a reference point to measure their own utility. This vertical equity concern, also known as distributive equity concern, mostly exists in the game relationship between a principal and an agent. This section introduces a decision-making model in which the superscript '-' indicates that two competing manufacturers have distributive equity concerns. We assumed that the utility function of the manufacturers is

$$
\bar{U}_{i}=\pi_{i}-\lambda\left(\pi_{r}-\pi_{i}\right), \quad i=1,2, j=3-i .
$$

The profit functions of the retailer and the whole supply chain are as follows:

$$
\begin{aligned}
\bar{\pi}_{r} & =\sum_{i=1}^{2}\left[\left(\bar{P}_{i}-C_{r}-\bar{W}_{i}\right)\left(Q_{o}-\bar{P}_{i}+\gamma \bar{P}_{j}\right)\right], \\
\bar{\pi} & =\sum_{i=1}^{2}\left[\pi_{i}-\lambda\left(\pi_{r}-\pi_{i}\right)+\left(\bar{P}_{i}-C_{r}-\bar{W}_{i}\right)\left(Q_{o}-\bar{P}_{i}+\gamma \bar{P}_{j}\right)\right] .
\end{aligned}
$$

Like the game process in Section 3.1, the optimal wholesale price, retail price, market demand, and optimal profit of the manufacturer, retailer, and whole supply chain were obtained by using backward induction. The procedure is as follows.

According to equation (21), the second derivative of the retailer's profit function with respect to retail price is a concave function since the system has a unique optimal retail price. Assuming $\partial \bar{\pi}_{r} / \partial P_{i}=0$, we get the retailer's response function:

$$
\bar{P}_{i}=\frac{Q_{o}+(1-\gamma)\left(W_{i}+C_{r}\right)}{2(1-\gamma)} .
$$

By substituting equation (23) for equation (20), the second derivative of the manufacturer's profit function with respect to wholesale price is a concave function, which shows that the supply chain system has a unique optimal wholesale price. Let $\partial \widetilde{U}_{i} / \partial \widetilde{W}_{i}=0$. From this, we get the optimal wholesale price of the manufacturers when they distribute the equity concern:

$$
\bar{W}_{i}^{*}=\frac{(1+2 \lambda) Q_{o}+(1+2 \lambda)(\gamma-1) C_{r}+(1+\lambda) C_{m}}{\Delta_{2}} .
$$

By substituting equation (24) for equation (23), we obtain the optimal retail price when the manufacturers distribute the equity concern:

$$
\bar{P}_{i}^{*}=\frac{(5 \lambda+3-4 \gamma \lambda-2 \gamma) Q_{o}+(1-\gamma)(1+\lambda)\left(C_{r}+C_{m}\right)}{2(1-\gamma) \Delta_{2}},
$$

$$
\bar{q}_{i}^{*}=\frac{(1+\lambda)\left[Q_{o}+(\gamma-1)\left(C_{r}+C_{m}\right)\right]}{2 \Delta_{2}} .
$$

Then, we put equations (24) and (25) into equations (20) and (22), and we get the optimal utility of the manufacturer when manufacturers distribute the equity concern:

$$
\bar{U}_{i}^{*}=\frac{(1+\lambda)^{2}(1+\lambda-\gamma-2 \gamma \lambda) A^{2}}{2(1-\gamma) \Delta_{2}^{2}} .
$$

We assumed that the two manufacturers are symmetric, and $\bar{U}_{i}^{*}=\bar{\pi}_{i}^{*}$ obviously exists. Then, we obtain the retailer's profit and the supply chain's profit when the manufacturers distribute the equity concern:

$$
\begin{aligned}
& \bar{\pi}_{r}^{*}=\frac{(1+\lambda)^{2} A^{2}}{2(1-\gamma) \Delta_{2}^{2}}, \\
& \bar{\pi}^{*}=\frac{(1+\lambda)^{2}(3-2 \gamma+2 \lambda-4 \gamma \lambda) A^{2}}{2(1-\gamma) \Delta_{2}^{2}},
\end{aligned}
$$

where $\Delta_{2}=3 \lambda+2-2 \gamma \lambda-\gamma$. It is easy to verify $\Delta_{2}>0$ under the assumption of the fairness concern coefficient $\lambda$ and the competition coefficient $\gamma$.

In summary, $\left(\bar{P}_{i}^{*}, \bar{W}_{i}^{*}\right)$ is the price strategy chosen by the retailer and manufacturer when competing manufacturers distribute the equity concern and $\bar{\pi}^{*}$ is the total profit of the supply chain in this case.

\section{Revenue-Sharing Contract When Competing Manufacturers Are Concerned about Fairness}

In this study, we examined a revenue-sharing contract in a competitive supply chain consisting of one retailer and two manufacturers, where the manufacturer had peer-induced fairness concerns and distributional fairness concerns, and analyzed the supply chain decision-making problem under different fairness preference modes. Here, the retailer was considered by setting the revenue sharing ratio; that is, the manufacturer offers the retailer a lower wholesale price, and the retailer shares a part of its revenue with the manufacturer to make up for the manufacturer's loss by lowering the wholesale price [33-37]. The revenue-sharing coefficient $\varphi$ is introduced here, which means that retailers share $\varphi$ part of their revenue with manufacturers. Because the two manufacturers are in competition with each other, and in order to facilitate the comparison of subsequent results, we assumed that both manufacturers enjoy proportional $\varphi / 2$ returns from retailers [38-43].

In order to make the supply chain under the decentralized decision-making modes reach the optimal level of centralized decision-making, firstly, a supply chain model under fair and centralized decision-making was established. The overall profit function of the manufacturer, retailer, and 
supply chain under the manufacturer's fair and centralized decision-making is as follows:

$$
\begin{aligned}
\pi_{i}= & \left(W_{i}-C_{m}\right)\left(Q_{o}-P_{i}+\gamma P_{j}\right), \quad i=1,2, j=3-i, \\
\pi_{r}= & \sum_{i=1}^{2}\left(P_{i}-C_{r}-W_{i}\right)\left(Q_{o}-P_{i}+\gamma P_{j}\right), \\
\pi= & \sum_{i=1}^{2}\left(W_{i}-C_{m}\right)\left(Q_{o}-P_{i}+\gamma P_{j}\right) \\
& +\sum_{i=1}^{2}\left(P_{i}-C_{r}-W_{i}\right)\left(Q_{o}-P_{i}+\gamma P_{j}\right) .
\end{aligned}
$$

The second-order derivative of the total profit $\pi$ of the supply chain with respect to the retail price $P_{i}$ is obtained by using the backward induction method: $\partial^{2} \pi / \partial P_{i}^{2}=4(\gamma-$ $1)<0$; that is, the supply chain has a unique optimal retail price.

Because the goal of centralized decision-making is to achieve profit optimization for the whole supply chain, the first derivative of the profit of the supply chain with respect to the retail price was obtained and made to be zero in this paper, $\partial \pi / \partial P_{i}=0$, and the optimal retail price of a supply chain under fair and centralized decision-making by a manufacturer was obtained, and the superscript " $c$ " was used to represent the optimal solution under the centralized decision:

$$
P_{i}^{c}=P_{j}^{c}=\frac{Q_{o}+(1-\gamma)\left(C_{m}+C_{r}\right)}{2(1-\gamma)} .
$$

\subsection{Manufacturers' Peer-Induced Fairness Concerns Are In-} troduced into Revenue-Sharing Contracts. This section discusses supply chain systems that introduce revenue-sharing contracts to coordinate supply chains to remove their dual marginalization effects when manufacturers are peer induced to fairness concerns. It makes the system efficiency under decentralized decision-making reach the best level under fair and centralized decision-making. Here, the superscript " $s$ " is introduced to mean the optimal decisionmaking of the revenue-sharing contract, and contract $\left(\tilde{W}_{i}^{s}, \varphi\right)$ was designed to coordinate a competitive supply chain in which the manufacturer has a tendency towards peer-induced fairness concerns. $\tilde{W}_{i}^{s}$ is the manufacturer's wholesale price at this time, and the revenue-sharing ratio $\varphi$ is given to the manufacturer by the retailer.

Conclusion 1. Supply chain coordination can be achieved when the wholesale price of the product satisfies $\widetilde{W}_{i}^{s}(\varphi)=$ $\left[(2-\varphi) C_{m}-\varphi C_{r}\right] / 2(1-\gamma)^{2}$ and $\tilde{U}_{i}^{s} \geq \widetilde{U}_{i}^{*}, \tilde{\pi}_{r}^{s}>\tilde{\pi}_{r}^{*}$, and the revenue-sharing contract can realize supply chain coordination when the manufacturers' fairness concerns and the competition intensity are related.

This paper proves that the utility functions of two manufacturers with peer-induced fairness concerns are as follows: when a revenue-sharing contract is introduced into the supply chain,

$$
\begin{array}{r}
\widetilde{U}_{i}^{*}=\sum_{i=1}^{2}\left[\frac{\varphi}{2} P_{i}^{s}\left(Q_{o}-\widetilde{P}_{i}^{s}+\gamma \widetilde{P}_{j}^{s}\right)\right]+\pi_{i}-\lambda\left(\pi_{j}-\pi_{i}\right), \\
i=1,2, j=3-i .
\end{array}
$$

Accordingly, in the case of a manufacturer's peer-induced fairness concern, the retailer's profit function with a revenue-sharing contract is

$$
\widetilde{\pi}_{r}^{s}=\sum_{i=1}^{2}\left[\left(1-\frac{\varphi}{2}\right) \widetilde{P}_{i}^{s}-C_{r}-\widetilde{W}_{i}^{s}\right]\left(Q_{o}-\widetilde{P}_{i}^{s}+\gamma \widetilde{P}_{j}^{s}\right) .
$$

Under the first-order optimality condition, the response function of the retailer is

$$
\left\{\begin{array}{l}
\widetilde{P}_{i}^{s}=\frac{Q_{o}}{2(1-\gamma)}+\frac{C_{r}}{2-\varphi}+\frac{1-\gamma}{2-\varphi}\left(\widetilde{W}_{i}^{s}-\gamma \widetilde{W}_{j}^{s}\right), \\
\widetilde{P}_{j}^{s}=\frac{Q_{o}}{2(1-\gamma)}+\frac{C_{r}}{2-\varphi}+\frac{1-\gamma}{2-\varphi}\left(\widetilde{W}_{j}^{s}-\gamma \widetilde{W}_{i}^{s}\right) .
\end{array}\right.
$$

In the coordinated state of the supply chain, the decision-making of both sides of the supply chain make the whole supply chain system reach a centralized state level of $\widetilde{P}_{i}^{s}=P_{i}^{c}$. Then, formula (36) is equal to formula (33), namely, $Q_{o} / 2(1-\gamma)+C_{r} / 2-\varphi+1-\gamma / 2-\varphi\left(\tilde{W}_{i}^{s}-\gamma \tilde{W}_{j}^{s}\right)=Q_{o}+(1-$ $\gamma)\left(C_{m}+C_{r}\right) / 2(1-\gamma)$. From this, we get

$$
\widetilde{W}_{i}^{s}(\varphi)=\frac{(2-\varphi) C_{m}-\varphi C_{r}}{2(1-\gamma)}+\gamma \widetilde{W}_{j}^{s}
$$

At the same time, because $\widetilde{P}_{j}^{s}=P_{j}^{c}$, that is, $Q_{o} / 2(1-\gamma)+$ $C_{r} / 2-\varphi+1-\gamma / 2-\varphi\left(\tilde{W}_{j}^{s}-\gamma \quad \widetilde{W}_{i}^{s}\right)=(1-\gamma)\left(C_{m}+C_{r}\right) / 2(1-$ $\gamma) Q_{o} / 2(1-\gamma)$, we get

$$
\tilde{W}_{j}^{s}(\varphi)=\frac{(2-\varphi) C_{m}-\varphi C_{r}}{2(1-\gamma)}+\gamma \tilde{W}_{j}^{s} .
$$

Simultaneously, formulas (37) and (38) provide the optimal wholesale price when the supply chain system introduces the revenue-sharing contract, taking into account the manufacturers' fairness concerns:

$$
\tilde{W}_{i}^{s}(\varphi)=\frac{(2-\varphi) C_{m}-\varphi C_{r}}{2(1-\gamma)^{2}} .
$$

Under the revenue-sharing contract mechanism, the wholesale price is determined when the manufacturer has a peer-induced fairness preference. Here, it was found that the contract can achieve supply chain coordination.

In this case, by substituting formula (36) for formula (39), we can obtain the optimal retail price when the manufacturer introduces the revenue-sharing contract:

$$
\widetilde{P}_{i}^{s}=\frac{Q_{o}}{2(1-\gamma)}+\frac{(2-\varphi) C_{m}+(1-\varphi) C_{r}}{2-\varphi} .
$$

At this point, substitution of formula (39) gives the retailer's profit as follows: 


$$
\begin{aligned}
\tilde{\pi}_{r}^{s}= & \left\{\frac{(1-\gamma)(2-\varphi) Q_{o}+\left[1-2(1-\gamma)^{2}\right]\left[(\varphi-2) C_{m}+\varphi C_{r}\right]}{2(1-\gamma)^{2}}\right\} \\
& \cdot\left\{\frac{Q_{o}}{2}-(1-\gamma)\left(C_{m}+\frac{C_{r}(1-\varphi)}{2-\varphi}\right)\right\} .
\end{aligned}
$$

At this point, substitution of formula (39) for formula (34) gives the manufacturer's utility as follows:

$$
\begin{aligned}
\widetilde{U}_{i}^{s}= & \left\{\frac{\varphi Q_{o}}{2(1-\gamma)}+\frac{\left[2(1-\gamma)^{2}(\varphi-1)+2-\varphi\right] C_{m}}{2(1-\gamma)^{2}}\right. \\
& \left.+\frac{\left[2 \varphi(1-\gamma)^{2}(1-\varphi)-\varphi(2-\varphi)\right] C_{r}}{2(2-\varphi)(1-\gamma)^{2}}\right\} \\
& \cdot\left[\frac{Q_{o}}{2}-(1-\gamma)\left(C_{m}+\frac{C_{r}(1-\varphi)}{2-\varphi}\right)\right] .
\end{aligned}
$$

Thus, according to formulas (39) and (40), the total utility of the supply chain at this point is obtained as follows:

$$
\begin{aligned}
\widetilde{U}^{s}= & \widetilde{\pi}_{r}^{s}+\sum_{i=1}^{2} \widetilde{U}_{i}^{s}=\left\{\frac{2 Q_{o}}{2(1-\gamma)}+C_{m}+\frac{\gamma(2-\gamma) C_{r}}{(1-\gamma)^{2}}\right\} \\
& \cdot\left[\frac{Q_{o}}{2}-(1-\gamma)\left(C_{m}+\frac{C_{r}(1-\varphi)}{2-\varphi}\right)\right] .
\end{aligned}
$$

In addition, after coordinating the revenue-sharing contracts, in order to achieve the goal of stimulating cooperation between enterprises in various nodes, it is necessary to ensure that the manufacturer's utility and the retailer's profit are not less than before the coordination, $\widetilde{U}_{i}^{s} \geq \widetilde{U}_{i}^{*}, \tilde{\pi}_{r}^{s} \geq \tilde{\pi}_{r}^{*}$. The range of values cannot be expressed directly after solving this equation, so a numerical simulation was carried out, and it was observed that the proportion of revenue-sharing $\varphi$ needs to satisfy certain relations with the fairness concern coefficient $\lambda$ and the competition intensity $\gamma$; otherwise, the manufacturer will refuse to accept the contract for reasons of fairness.

4.2. Manufacturer's Distributional Fairness Concerns Are Introduced into Revenue-Sharing Contracts. Here, we discuss supply chain systems that introduce revenue-sharing contracts to coordinate supply chains to remove their dual marginalization effects when manufacturers' distributional fairness concerns arise. It makes the system efficiency under decentralized decision-making reach the best level under fair and centralized decision-making. In this study, the revenuesharing contract $\left(\bar{W}_{i}^{s}, \varphi\right)$ was used to coordinate the competitive supply chain in which the manufacturer has a tendency towards distributional fairness concerns, which is the wholesale price of the manufacturer $\left(\bar{W}_{i}^{s}\right)$ and the revenue-sharing proportion $\varphi$ of the retailer.

Conclusion 2. A revenue-sharing contract can achieve supply chain coordination when the wholesale price is satisfied $\bar{W}_{i}^{s}(\varphi)=\left[(2-\varphi) C_{m}-\varphi C_{r}\right] / 2(1-\gamma)^{2}, \quad \bar{U}_{i}^{s} \geq \bar{U}_{i}^{*}$, $\bar{\pi}_{r}^{s} \geq \bar{\pi}_{r}^{*}$, and the coordination conditions are related to fairness concerns and the competition intensity between the two manufacturers.

This paper proves that the utility functions of two manufacturers with distributional fairness concerns are as follows, when revenue-sharing contracts are introduced into the supply chain:

$$
\begin{array}{r}
\bar{U}_{i}^{s}=\sum_{i=1}^{2}\left[\frac{\varphi}{2} \bar{P}_{i}^{s}\left(Q_{o}-\bar{P}_{i}^{s}+\gamma \bar{P}_{j}^{s}\right)\right]+\pi_{i}-\lambda\left(\pi_{r}-\pi_{i}\right), \\
i=1,2, j=3-1 .
\end{array}
$$

In the case of the manufacturer's fairness concern, the retailer's profit function with a revenue-sharing contract is as follows:

$$
\bar{\pi}_{r}^{s}=\sum_{i=1}^{2}\left[\left(1-\frac{\varphi}{2}\right) \bar{P}_{i}^{s}-C_{r}-\bar{W}_{i}^{s}\right]\left(Q_{o}-\bar{P}_{i}^{s}+\gamma \bar{P}_{j}^{s}\right) .
$$

The retailer's response function is derived from the firstorder optimality condition:

$$
\left\{\begin{array}{l}
\bar{P}_{i}^{s}=\frac{Q_{o}}{2(1-\gamma)}+\frac{C_{r}}{2-\varphi}+\frac{(1-\gamma)}{2-\varphi}\left(\bar{W}_{i}^{s}-\gamma \bar{W}_{j}^{s}\right), \\
\bar{P}_{j}^{s}=\frac{Q_{o}}{2(1-\gamma)}+\frac{C_{r}}{2-\varphi}+\frac{(1-\gamma)}{2-\varphi}\left(\bar{W}_{j}^{s}-\gamma \bar{W}_{i}^{s}\right) .
\end{array}\right.
$$

In the coordinated state of the supply chain, the decisionmaking of both sides of the supply chain makes the whole supply chain system reach a centralized state level of $\bar{P}_{i}^{s}=P_{i}^{c}$; that is, formula (46) is equal to (33), namely, $\left(Q_{o} / 2(1-\gamma)\right)+$ $\left(C_{r} /(2-\varphi)\right)+((1-\gamma) /(2-\varphi))\left(\bar{W}_{i}^{s}-\gamma \bar{W}_{j}^{s}\right)=\left(Q_{o} / 2(1-\gamma)\right)$. From this, we get

$$
\bar{W}_{i}^{s}(\varphi)=\frac{(2-\varphi) C_{m}-\varphi C_{r}}{2(1-\gamma)}+\gamma \bar{W}_{j}^{s} .
$$

At the same time, because $\overline{P_{j}^{s}}=P_{j}^{c}$, namely, $\left(Q_{o} / 2(1-\right.$ $\gamma))+\left(C_{r} /(2-\varphi)\right)+((1-\gamma) /(2-\varphi))\left(\bar{W}_{j}^{s}-\gamma \bar{W}_{i}^{s}\right)=((1-\gamma)$ $\left.\left(C_{m}+C_{r}\right) / 2(1-\gamma)\right)\left(Q_{o} / 2(1-\gamma)\right)$, we get

$$
\bar{W}_{j}^{s}(\varphi)=\frac{(2-\varphi) C_{m}-\varphi C_{r}}{2(1-\gamma)}+\gamma \bar{W}_{j}^{s} .
$$

Simultaneously, formulas (47) and (48) result in

$$
\bar{W}_{i}^{s}(\varphi)=\frac{(2-\varphi) C_{m}-\varphi C_{r}}{2(1-\gamma)^{2}} .
$$

Under the revenue-sharing contract mechanism, the manufacturer has the wholesale price when the distributional fairness preference is established. Here, it was found that the contract can realize coordination of the supply chain.

In this case, substituting formula (46) for formula (49) provides the optimal retail price when the manufacturer introduces a revenue-sharing contract: 


$$
\bar{P}_{i}^{s}=\frac{Q_{o}}{2(1-\gamma)}+\frac{(2-\varphi) C_{m}+(1-\varphi) C_{r}}{2-\varphi} .
$$

At this point, the substitution of formula (50) for formula (45) yields the retailer's profit as follows:

$$
\begin{aligned}
\bar{\pi}_{r}^{s}= & \left\{\frac{(1-\gamma)(2-\varphi) Q_{o}+\left[1-2(1-\gamma)^{2}\right]\left[(\varphi-2) C_{m}+\varphi C_{r}\right]}{2(1-\gamma)^{2}}\right\} \\
& \cdot\left[\frac{Q_{o}}{2}-(1-\gamma)\left(C_{m}+\frac{C_{r}(1-\varphi)}{2-\varphi}\right)\right] .
\end{aligned}
$$

At this point, substituting expression (50) for expression (44) provides the manufacturer's utility as follows:

$$
\begin{aligned}
\bar{U}_{i}^{s}= & \left\{\frac{C_{r}\left(4 \lambda-\varphi^{2}-6 \varphi \lambda-4 \varphi \gamma+4 \varphi^{2} \gamma-8 \gamma \lambda+2 \varphi \gamma^{2}-2 \varphi^{2} \gamma^{2}+4 \gamma^{2} \lambda+3 \varphi^{2} \lambda\right)}{2(2-\varphi)(1-\gamma)^{2}}+\frac{(\varphi-2 \lambda) Q_{o}}{2(1-\gamma)}+(\varphi-3 \lambda) C_{m}\right\} \\
& \cdot\left[\frac{Q_{o}}{2}-(1-\gamma)\left(C_{m}+\frac{C_{r}(1-\varphi)}{2-\varphi}\right)\right] .
\end{aligned}
$$

So, according to formulas (51) and (52), the total utility of the supply chain is $\bar{U}^{s}=\bar{\pi}_{r}^{s}+\sum_{i=1}^{2} \bar{U}_{i}^{s}$.

In addition, after coordinating the revenue-sharing contracts, in order to achieve the goal of stimulating cooperation between enterprises in various nodes, it is necessary to ensure that the manufacturer's utility and the retailer's profit are not less than before coordination, $\bar{U}_{i}^{s} \geq \bar{U}_{i}^{*}, \bar{\pi}_{r}^{s} \geq \bar{\pi}_{r}^{*}$. The range of values cannot be expressed directly after solving this equation, so a numerical simulation was carried out, and it was found that the proportion of revenue sharing $\varphi$ needs to satisfy certain relations with the fairness concern coefficient $\lambda$ and the competition intensity $\gamma$; otherwise, the manufacturer will refuse to accept the contract for reasons of fairness.

\section{Numerical Example}

In order to verify the correctness of the proposed model and compare the effectiveness of revenue-sharing contracts more intuitively, the above conclusions were simulated. The assignment was as follows:

Let the cost of production for the manufacturer be $C_{m}=15$, the cost of sales for the retailer be $C_{r}=5$, and the market demand function for the product be $q_{i}=140+P_{i}-0.3 P_{j}$.
5.1. Numerical Analysis of Supply Chain with a RevenueSharing Contract considering Manufacturer's Peer-Induced Fairness Concerns. The retailer's and manufacturer's utilities after decentralized decision-making and the revenue-sharing contract were compared when the manufacturer's fairness concern level and revenue sharing coefficient changed, as shown in Table 2.

The results in Table 2 show that $\varphi=0.1$, which means that the manufacturer's utility with a revenue-sharing contract cannot exceed the level of centralized decisionmaking; that is, revenue-sharing contracts cannot coordinate a supply chain in which the manufacturer's peer-induced concerns are met. When the retailer's revenue-sharing ratio is 0.7 , with the change in $\lambda$, the utility of the manufacturer and the retailer with a revenue-sharing contract was effectively improved. The results support conclusion 1 that the retailer's revenue-sharing ratio needs to satisfy certain conditions with the manufacturer's fairness concern coefficient $\widetilde{U}_{i}^{s} \geq \widetilde{U}_{i}^{*}, \widetilde{\pi}_{r}^{s} \geq \widetilde{\pi}_{r}^{*}$. The contract is to coordinate the supply chain.

Then, when the conditions are met $\widetilde{U}_{i}^{s} \geq \widetilde{U}_{i}^{*}, \tilde{\pi}_{r}^{s} \geq \widetilde{\pi}_{r}^{*}$, how will the change in the retailers' revenue-sharing parameters affect the supply chain system? We used $\lambda=0.2$ to observe the influence of the retailer's income distribution on the supply chain.

Based on the validity of $\widetilde{U}_{i}^{s} \geq \widetilde{U}_{i}^{*}, \tilde{\pi}_{r}^{s} \geq \tilde{\pi}_{r}^{*}, 0<\varphi<1$, we obtained

$$
\begin{aligned}
& \widetilde{U}_{i}^{s}=\left[\left(100+\frac{35-20 \varphi}{2-\varphi}\right) \varphi+15.61224490-20.40816327 \varphi\right]\left[70-\frac{0.7(35-20 \varphi)}{2-\varphi}\right], \\
& \widetilde{U}_{i}^{*}=\frac{A^{2}(3+3 \lambda-\gamma \lambda-2 \gamma)(1+\gamma \lambda+\lambda)}{2(1-\gamma) \Delta_{1}^{2}}=2721.6 .
\end{aligned}
$$


TABLE 2: Comparison of utility between two decision-making situations in manufacturer's peer-induced equity concerns.

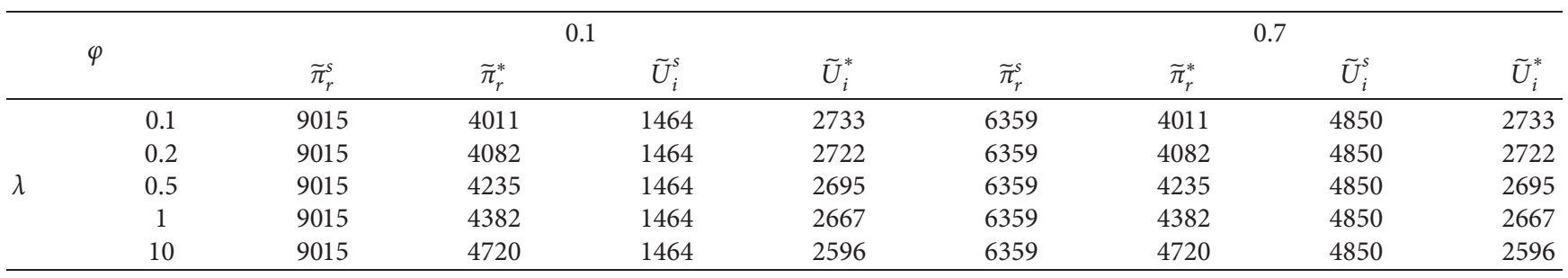

Therefore, $\varphi \leq 1.53$ :

$$
\begin{aligned}
\tilde{\pi}_{r}^{s}= & 2\left[\left(1-\frac{\varphi}{2}\right)\left(100+\frac{35-20 \varphi}{2-\varphi}\right)\right]\left[70-\frac{0.7(35-20 \varphi)}{2-\varphi}\right] \\
& -2(35.61224490-20.40816327)\left[70-\frac{0.7(35-20 \varphi)}{2-\varphi}\right],
\end{aligned}
$$$$
\tilde{\pi}_{r}^{*}=\frac{A^{2}(1+\gamma \lambda+\lambda)^{2}}{2(1-\gamma) \Delta_{1}^{2}}=4082.4
$$

Therefore, $\varphi \geq 0.56$. In summary, the revenue-sharing ratio of this time value range was $0.56 \leq \varphi<1$ (Table 3).

Observing the results of the table above, it can be seen that, in the range of the effective revenue-sharing ratio, the retail and wholesale prices both decreased with the increase in the revenue-sharing ratio between retailers and manufacturers, and at the same time, the profits of retailers decreased accordingly, but the overall utility of manufacturers and supply chains improved markedly. Obviously, the manufacturers and retailers can effectively increase the demand of products and improve the overall efficiency of the supply chain after considering the revenue-sharing contract by decreasing the price. In real life, many enterprises take the strategy of small profits and quick turnover to maximize the overall benefit.

In order to compare the utility and decision changes of the supply chain with revenue-sharing contracts, Maple 17.0 was used (Figure 1) to analyze the impact of revenue-sharing contract on the optimal decisions which considering manufacturer's peer-induced fairness concerns.

The results in Figure 1 show that, in the range of effective revenue sharing, for example, in (a), the wholesale price of the manufacturer at this time was less than the decentralized decision, and with the increase of retailer's revenue-sharing proportion, the wholesale price of manufacturer to retailer will also decrease, (b). Because of the reduction of the wholesale cost, the retail price of the retailer decreased correspondingly, which had a negative correlation with the revenue-sharing coefficient and was less than the retail price when the retailer made the decentralized decision; (c) there was a negative correlation between retailer's profit and the proportion of revenue sharing, but the total revenue was obviously higher than that of decentralized decision-making. As shown in Figure 1(d), there was a positive correlation between the utility of the manufacturer and the proportion of revenue sharing. Although the retailer's revenue decreased with the proportion of revenue sharing, the effective improvement
TABLE 3: Effect of variation in other parameters when manufacturers are peer-induced to fairness concerns.

\begin{tabular}{lccccc}
\hline$\varphi$ & $\widetilde{P}_{i}^{s}$ & $\widetilde{W}_{i}^{s}$ & $\tilde{\pi}_{r}^{s}$ & $\widetilde{U}_{i}^{s}$ & $\widetilde{U}^{s}$ \\
\hline 0.56 & 116.5 & 19.2 & 6978.5 & 4057.4 & 15093.2 \\
0.61 & 116.4 & 18.2 & 6757.3 & 4340.2 & 15437.7 \\
0.66 & 116.3 & 17.1 & 6536.1 & 4623.3 & 15782.7 \\
0.71 & 116.1 & 16.1 & 6314.9 & 4906.7 & 16128.3 \\
0.76 & 116.0 & 15.1 & 6093.8 & 5190.4 & 16474.5 \\
0.81 & 115.8 & 14.1 & 5872.7 & 5474.4 & 16821.4 \\
0.86 & 115.6 & 13.1 & 5651.7 & 5758.7 & 17169.1 \\
0.91 & 115.4 & 12.0 & 5430.7 & 6043.5 & 17517.7 \\
0.96 & 115.2 & 11.0 & 5209.9 & 6328.6 & 17867.2 \\
\hline
\end{tabular}

of the manufacturer's utility offset the decrease of the proportion of revenue sharing. Thus, the overall utility of the supply chain in Figure 1(e) increased with the increase in the revenue sharing ratio coefficient. Therefore, the shared contract designed by this research can not only improve the retailer's and manufacturer's revenue but also enhance the total utility of the channel, ensuring a longterm, stable, and cooperative relationship of the node enterprises and strengthening the overall competitiveness of the supply chain. In addition, the numerical simulation showed that the range of the revenue-sharing ratio needs to be greater than or equal to 0.56 , which indicates that, under the contract mechanism, the profit ratio of the supply chain to the manufacturer concerned with peer-induced fairness should be at least higher than 0.56 ; otherwise, coordination of the supply chain cannot be realized.

\subsection{Numerical Analysis of Supply Chain with Revenue-Sharing} Contract with Manufacturer's Distributional Fairness Concerns. The change in the utility of the retailer, the manufacturer, and the supply chain as a whole is shown in Table 4, for when the manufacturer's equity concern and revenue-sharing coefficient change.

The results in Table 4 show that, at that time $\varphi=0.7$, the total utility of the manufacturer and the supply chain showed a negative increase with the increase in $\lambda$. Similarly, when other $\varphi$ values were taken, the same situation also occurred; that is, revenue-sharing contracts could not coordinate the supply chain in which the manufacturer had distributional fairness concerns. This result supports conclusion 2 that the retailer's revenue-sharing proportion needs to satisfy certain conditions with the manufacturer's concern coefficient of fairness $\bar{U}_{i}^{s} \geq \bar{U}_{i}^{*}, \bar{\pi}_{r}^{s} \geq \bar{\pi}_{r}^{*}$, and the contract needs to coordinate the supply chain. 


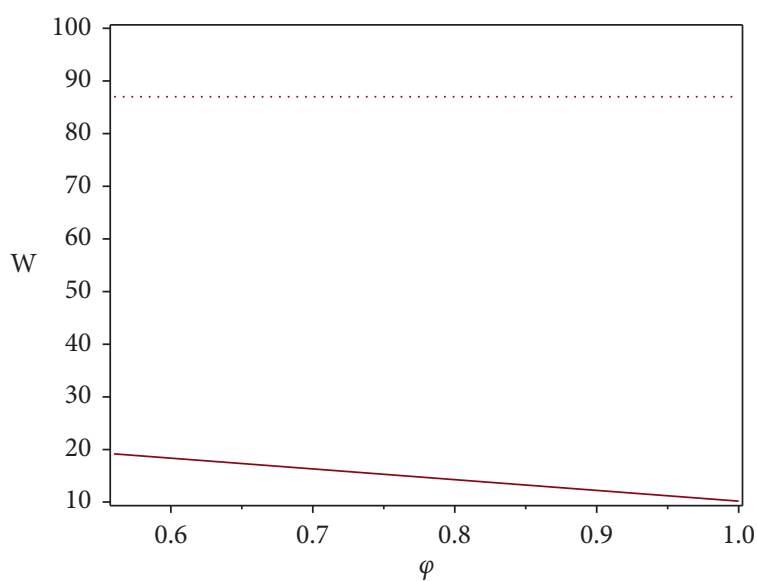

- Wholesale price under peer-induced and RS Wholesale price under peer-induced and decentralized decision

(a)



(c)

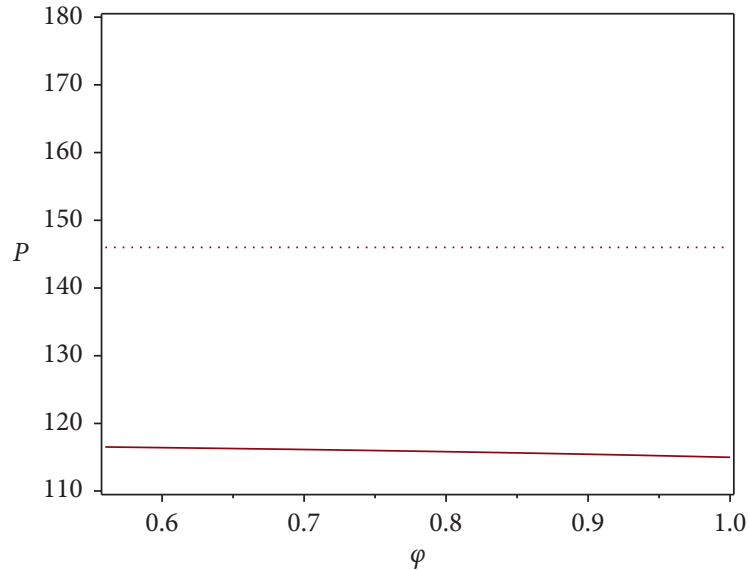

- Retail price under peer-induced and RS

..... Retail price under peer-induced and decentralized decision

(b)



Manufacturer's utility under peer-induced and RS Manufacturer's utility under peer-induced and decentralized decision

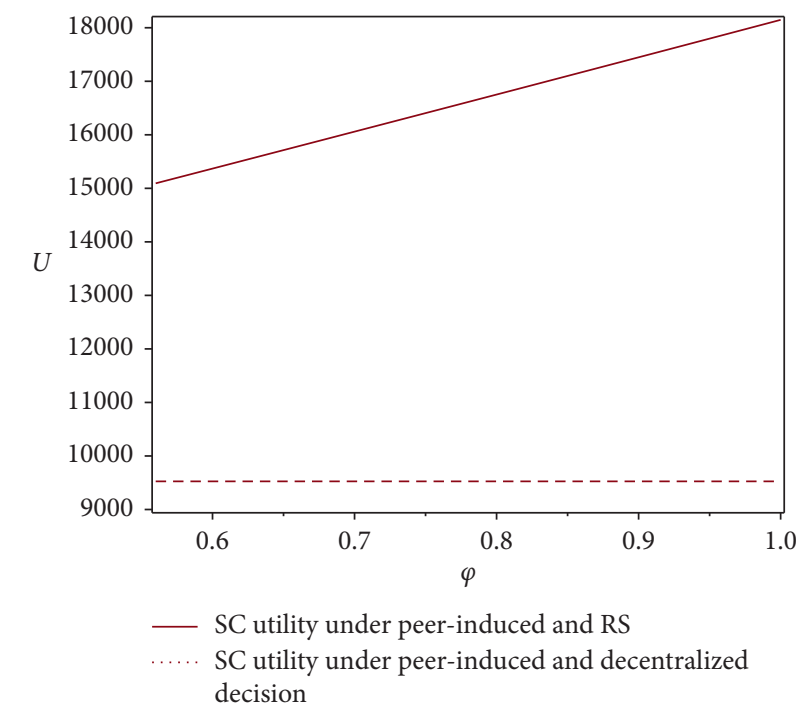

(d)

(e)

FIGURE 1: Effect of RS contract on supply chain of manufacturer's peer-to-peer-induced equity concern: (a) the impact of RS on W-Price; (b) the impact of RS on R-Price; (c) the influence of RS on retailer profit; (d) the influence of RS on manufacturer profit; (e) the influence of RS on the total utility of supply chain. 
TABLE 4: Impact of changes in other parameters.

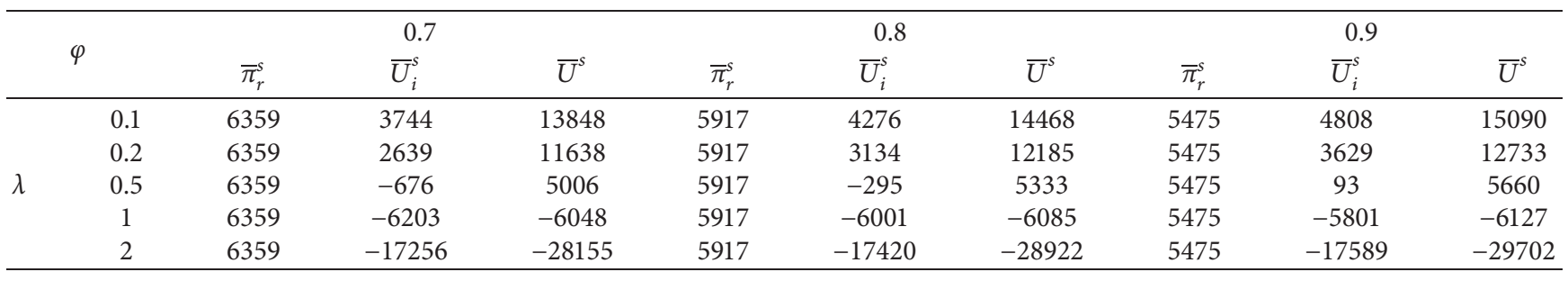

In addition, in the range of the effective revenuesharing ratio, when the manufacturer's fairness concerns were constant, the retail price and the wholesale price decreased with the increase in the retailer's revenuesharing ratio. The retailer's profit decreased correspondingly, but the total utility of the manufacturer and the supply chain increased obviously. When the proportion of the retailer's revenue sharing was constant, the utility of the supply chain and the manufacturer decreased, or were even negative, with the increase in the two manufacturers' fairness concerns, and the retailer's profits were unaffected. The two manufacturers' fairness concerns cannot increase without limitation, the high fairness concerns will make its own and whole supply chain's profits reduce. In real life, the benefits of both sides only can be optimized by considering the appropriate fairness concern.

In order to examine more intuitively the impact of changes in the manufacturer's fairness concerns on the utility of the supply chain, Maple 17.0 was used to analyze impact of $\lambda$ on the optimal decision under revenue-sharing contract, as shown in Figure 2 (since the retailer's utility is not affected by the level of fairness concerns, it is not analyzed here).

The results in Figure 2 show that the overall utility of both the manufacturer and the supply chain was affected by the degree of equity concerns in the effective revenuesharing range, and there was a negative correlation between $\lambda$ with the two and an upper bound. The overall utility for both the manufacturer and the supply chain above this value will be negative. It can be seen that the manufacturer with a preference for distributional fairness concerns should reduce its concerns when it receives the shared profits from retailers to ensure its utility as well as that of the whole supply chain.

Based on the above findings, when the conditions are met $\bar{U}_{i}^{s} \geq \bar{U}_{i}^{*}, \bar{\pi}_{r}^{s} \geq \bar{\pi}_{r}^{*}$, how will the change in retailers' revenue sharing parameters affect the supply chain system? We used $\lambda=0.2$ to observe the influence of the retailer's income distribution on the supply chain.

Based on the validity of $\bar{U}_{i}^{s} \geq \bar{U}_{i}^{*}, \bar{\pi}_{r}^{s} \geq \bar{\pi}_{r}^{*}, 0<\varphi<1$, we obtained

$$
\begin{aligned}
\bar{U}_{i}^{s}= & 4714.29 * \varphi+\frac{1261.71 * \varphi-457.14 * \varphi^{2}-808}{2-\varphi} \\
& -\frac{1249.5 * \varphi+1092 * \varphi^{2}-280 * \varphi^{3}+343}{(2-\varphi)^{2}}-491.43, \\
\bar{U}_{i}^{*}= & \frac{(1+\lambda)^{2}(1+\lambda-\gamma-2 \gamma \lambda) A^{2}}{2(1-\gamma) \Delta_{2}^{2}}=2680.1, \\
\bar{\pi}_{r}^{s}= & 9014.29-4142.86 * \varphi+\frac{1745-1997.14 * \varphi+571.43 * \varphi^{2}}{2-\varphi} \\
& -\frac{2817.5 * \varphi+1540 * \varphi^{2}-280 * \varphi^{3}+1715}{(2-\varphi)^{2}}, \\
\bar{\pi}_{r}^{*}= & \frac{(1+\lambda)^{2} A^{2}}{2(1-\gamma) \Delta_{2}^{2}}=3436.1 .
\end{aligned}
$$

In summary, the revenue-sharing ratio value range is $0.71<\varphi<1$.

According to the range of the revenue-sharing proportion, in this study, it was assumed that, for $\varphi$, the change in the step length is 0.1 . The optimal decision-making and utility change of the supply chain were obtained when the revenue sharing proportion coefficient was different, as shown in Table 5.

Table 5 shows that, in the range of the effective revenue sharing ratio, the retail and wholesale prices both decreased with the increase in the revenue-sharing ratio between retailers and manufacturers, and at the same time, the profits of the retailers decreased accordingly. However, the overall utility of the manufacturers and supply chains improved markedly.

To make a more intuitive comparison of the utility and decision-making changes in a supply chain with revenuesharing contracts, Maple 17.0 was used to analyze the impact of revenue-sharing contract on the optimal decisions with manufacturer distributional fairness concerns (Figure 3).

As can be seen from Figure 3 that, in the range of the effective revenue sharing ratio, (a) the wholesale price of the manufacturer was significantly lower than that of 


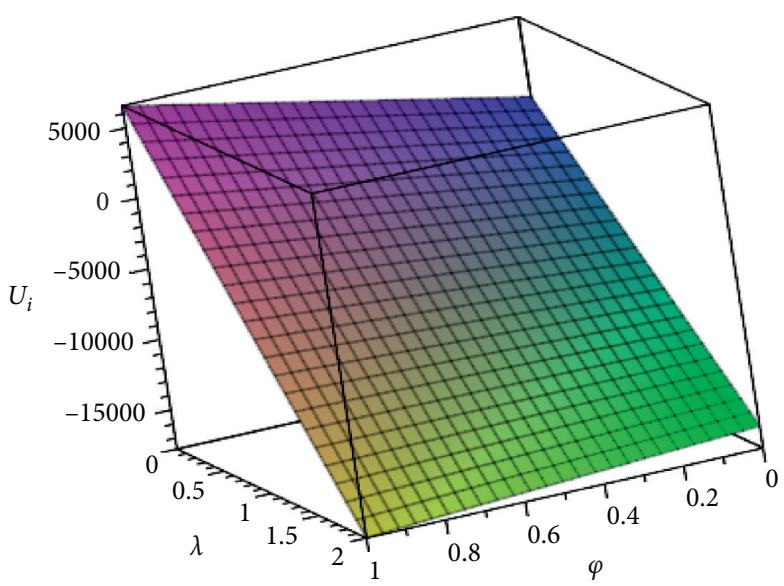

(a)

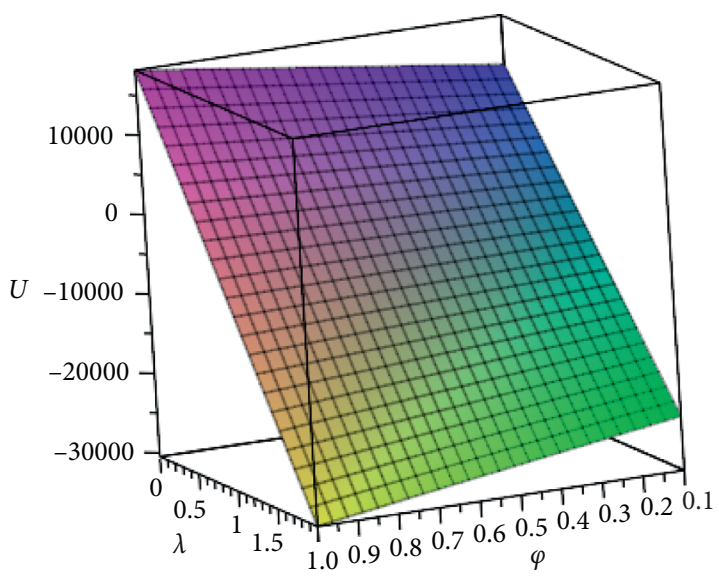

(b)

FIGURE 2: The impact of (a) $\lambda$ and (b) $\varphi$ on the utility of supply chains for manufacturers' distributional fairness concerns under RS.

TABLE 5: Effect of change in other parameters when manufacturers allocate fairness concerns.

\begin{tabular}{|c|c|c|c|c|c|}
\hline$\varphi$ & $\bar{P}_{i}^{S}$ & $\bar{W}_{i}^{s}$ & $\bar{\pi}_{r}^{s}$ & $\bar{U}_{i}^{s}$ & $\bar{U}^{s}$ \\
\hline 0.71 & 116.1 & 16.1 & 6314.9 & 2688.7 & 11692.4 \\
\hline 0.76 & 116.0 & 15.1 & 6093.8 & 2935.9 & 11965.6 \\
\hline 0.81 & 115.8 & 14.1 & 5872.7 & 3183.3 & 12239.3 \\
\hline 0.86 & 115.6 & 13.1 & 5651.7 & 3430.8 & 12513.3 \\
\hline 0.91 & 115.4 & 12.0 & 5430.7 & 3678.5 & 12787.8 \\
\hline 0.96 & 115.2 & 11.0 & 5209.9 & 3926.4 & 13062.8 \\
\hline
\end{tabular}

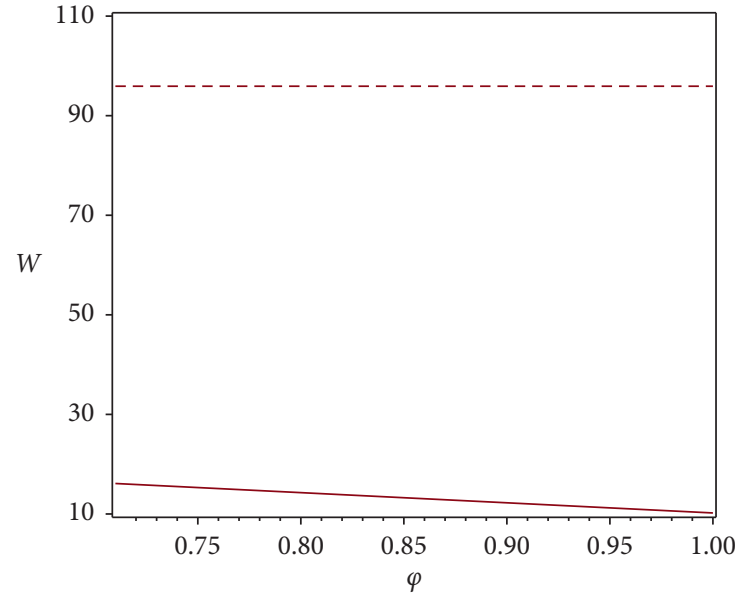

- Wholesale price under distribution and RS Wholesale price under distribution and decentralized decision



(b)

Figure 3: Continued. 


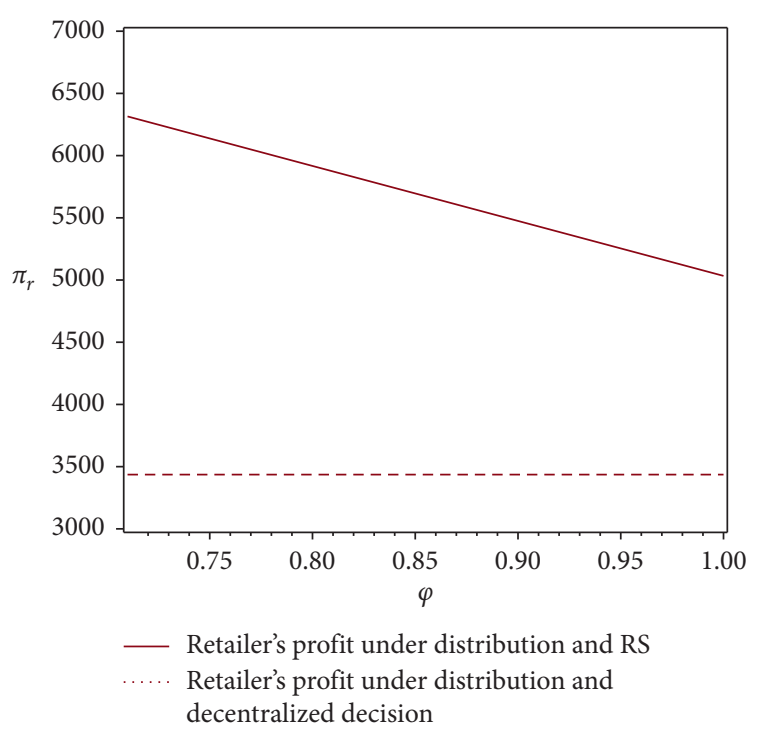

(c)

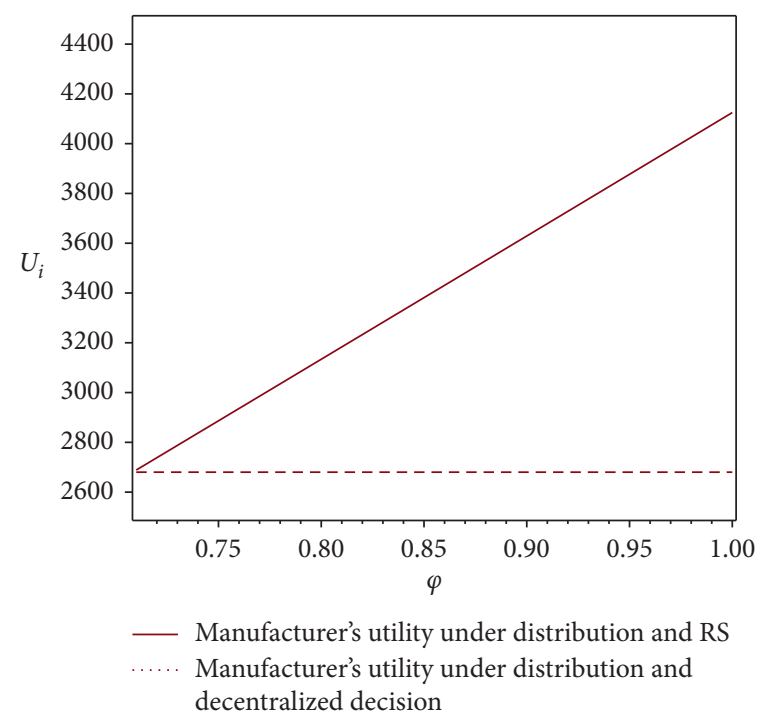

(d)

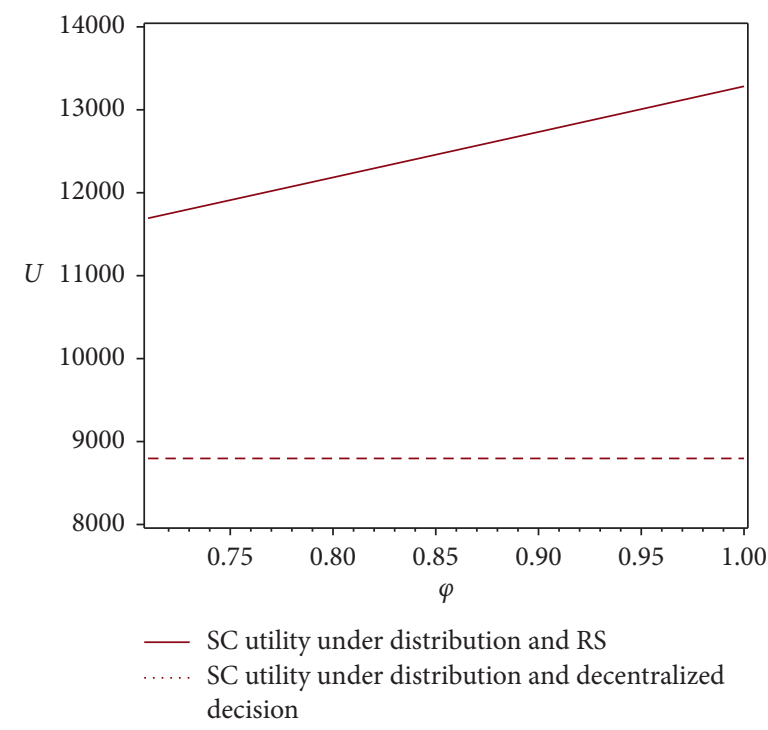

(e)

FIGURE 3: Impact of RS contracts on supply chains of manufacturer's distributional fairness concerns: (a) the impact of RS on W-Price; (b) the impact of RS on R-Price; (c) the influence of RS on retailer profit; (d) the influence of RS on manufacturer profit; (e) the influence of RS on the total utility of supply chain.

decentralized decision-making, and as the share ratio of the retailer increased, the wholesale price of the manufacturer as a reward also decreased. (b) The retail price was also reduced by the reduction of the wholesale cost, which was less than the price at the time of its decentralized decision-making and decreased with the increase in the revenue sharing ratio. As shown in Figure 3(c), there was a negative correlation between the retailer's profit and the proportion of revenue sharing, but the total revenue was obviously higher than that of decentralized decision-making. As shown in Figure 3(d), there was a positive correlation between the utility of the manufacturer and the proportion of revenue sharing. Although the retailer's revenue decreased with the proportion of revenue sharing, the effective improvement of the manufacturer's utility offset the decrease of the proportion of revenue sharing. Therefore, the overall utility of the supply chain (Figure 3(e)) increased with the increase in the revenue-sharing ratio coefficient. Therefore, the sharing contract designed in this study can not only effectively improve the utility of retailers and manufacturers but also enhance the total utility of the channel to ensure that node enterprises have long-term, stable, and cooperative relationships and to strengthen the overall competitiveness of the supply chain. In addition, the range of the revenue sharing ratio obtained by numerical simulation needs to be greater than or equal to 0.71 , which indicates that, under the contract mechanism, the profit proportion of the supply chain for the manufacturer concerned with distributional fairness should be at 
least higher than 0.71 ; otherwise, supply chain coordination cannot be achieved. So, conclusion 2 is confirmed.

\section{Conclusion}

This study was based on supply chain coordination and dynamic game theory, as well as on a decentralized decisionmaking pricing model. Here, we constructed two game models-the manufacturer's peer-induced fairness concern model and the manufacturer's distributional fairness concern model-by introducing a revenue sharing contract mechanism, and the influence of a revenue sharing contract on the pricing decisions and profit distribution of a competitive supply chain considering fairness concerns was analyzed. The research found that, in the range of effective revenue sharing ratio, with the increase in retailer's revenue sharing ratio to manufacturer, the retail price, wholesale price, and retailer's profit under two game models will both decrease correspondingly, but the total utility of manufacturer and supply chain will be significantly improved. Obviously, the retailer sharing revenue can reduce the double marginal effect by adopting the strategy of the small profits but quick turnover.

The results of this study also show that when a revenuesharing contract is introduced into a supply chain, whether it is a supply chain where the manufacturer induces the fairness concerns or a supply chain where the manufacturer distributes the fairness concerns, each model has its own revenue sharing distribution interval, and the proportion is closely related to the level of fairness concerns of competing manufacturers and product competition intensity, which can effectively improve the total benefit of each node enterprise and channel. It will ensure the long-term stable cooperation relationship of node enterprises and strengthens the overall competitiveness of the supply chain.

Although our study offered several innovations, there are still a few deficiencies remaining. For example, the research established the supply chain consisting of two homogeneous competitive manufacturers and one retailer, but the game in real life often involves multiple participants, which is more complex. Therefore, the future research can expand the supply chain system to the competition between multiple manufacturers and retailers. In addition, in the field of supply chain coordination, there are other contracts that can be used for reference, such as sales rebate, two-step pricing, and quantity discount. The follow-up research can explore a variety of contract coordination modes of competitive supply chain.

\section{Data Availability}

The data used to support the findings of this study are included within the article.

\section{Conflicts of Interest}

The authors declare that they have no conflicts of interest.

\section{Acknowledgments}

The authors are grateful to the support of Youth Foundation of Ministry of Education of China (19YJC630141),
Chongqing Social Science Planning Project (2018BS84), and the Scientific and Technological Research Program of Chongqing Municipal Education Commission (KJQN201800832).

\section{References}

[1] D. Kahneman, J. L. Knetsch, and R. H. Thaler, "Fairness and the assumptions of economics," The Journal of Business, vol. 59, no. 4, pp. 285-300, 1986.

[2] L. Zhang, H. Zhou, Y. Liu, and R. Lu, "Optimal environmental quality and price with consumer environmental awareness and retailer's fairness concerns in supply chain," Journal of Cleaner Production, vol. 213, pp. 1063-1079, 2019.

[3] B. A. Pasternack, "Commentary-optimal pricing and return policies for perishable commodities," Marketing Science, vol. 27, no. 1, pp. 131-132, 2008.

[4] A. A. Tsay and W. S. Lovejoy, "Quantity flexibility contracts and supply chain performance," Manufacturing \& Service Operations Management, vol. 1, no. 2, pp. 89-111, 1999.

[5] S. Yan, S. Li, and Y. Bian, "Supply chain coordination contracts based on warranty service," Journal of Systems Engineering, vol. 28, no. 5, pp. 677-685, 2013.

[6] P. Ma, K. W. Li, and Z.-J. Wang, "Pricing decisions in closedloop supply chains with marketing effort and fairness concerns," International Journal of Production Research, vol. 55, no. 22, pp. 6710-6731, 2017.

[7] C. Luo and X. Tian, "Risk averse supply chain coordination with revenue-sharing contract," Journal of Systems Engineering, vol. 30, no. 2, pp. 210-217, 2015.

[8] L.-X. Xu, Q. Xu, and X. Liu, "Supply chain contracts based on competition-cooperation game in multiple manufacturers," Industrial Engineering and Management, vol. 21, no. 4, pp. 67-73, 2016.

[9] H.-Y. Jian and M.-L. Xu, "Models and their experiments of supply chain contracts based on CVaR," Journal of Management Sciences in China, vol. 18, no. 10, pp. 56-68, 2015.

[10] J. Liu and S.-L. Shu, "Coordination contract of service supply chain considering fairness concerns," Control and Decision, vol. 30, no. 1, pp. 98-104, 2015.

[11] L.-Q. Zhao and J.-W. Xu, "Contract design for coordination conflict of dual channels supply chain based on E-market," Chinese Journal of Management Science, vol. 22, no. 5, pp. 61-68, 2014.

[12] B. Dan and G. Xu, "Revenue sharing contract for dual-channel supply chain coordination with stochastic demand," Journal of Systems Engineering, vol. 28, no. 4, pp. 514-521, 2013.

[13] X. Cao, B. Zheng, and H. Wen, "Pricing and coordination decision of the dual channel closed-loop supply chain considering the customer preference," Chinese Journal of Management Science, vol. 23, no. 6, pp. 107-117, 2015.

[14] X.-X. Zheng, D.-F. Li, Z. Liu, F. Jia, and J.-B. Sheu, "Coordinating a closed-loop supply chain with fairness concerns through variable-weighted shapley values," Transportation Research Part E: Logistics and Transportation Review, vol. 126, pp. 227-253, 2019.

[15] A. Sharma, G. Dwivedi, and A. Singh, "Game-theoretic analysis of a two-echelon supply chain with option contract under fairness concerns," Computers \& Industrial Engineering, vol. 137, Article ID 106096, 2019.

[16] X. Wang and X. Wang, "The coordination of supply chain with bilateral asymmetric information by considering risk aversion of retailer," Chinese Journal of Management Science, vol. 23, no. 3, pp. 97-107, 2015. 
[17] I. Giannoccaro and P. Pontrandolfo, "Supply chain coordination by revenue sharing contracts," International Journal of Production Economics, vol. 89, no. 2, pp. 131-139, 2004.

[18] D. Hong, Y. Ma, and D. Ni, "Compensation strategy for supply chain coordination in gray markets," Journal of Systems Engineering, vol. 33, no. 1, pp. 103-115, 2018.

[19] X. Baolin, S. Cui, S. Ji, and R. Qiu, "Combined contract model of three-echelon supply chain based on risk aversion of retailer under yield and demand uncertainties condition," Chinese Journal of Management Science, vol. 26, no. 11, pp. 114-123, 2018.

[20] Y. Zhang and Z. Wang, "Study on three level dual-channels with joint coordination contract," Chinese Journal of Management Science, vol. 23, no. S1, pp. 537-542, 2015.

[21] Z. Liu, K. W. Li, B.-Y. Li, J. Huang, and J. Tang, "Impact of product-design strategies on the operations of a closed-loop supply chain," Transportation Research Part E: Logistics and Transportation Review, vol. 124, pp. 75-91, 2019.

[22] J. Jian, Y. Guo, L. Jiang, Y. An, and J. Su, "A multi-objective optimization model for green supply chain considering environmental benefits," Sustainability, vol. 11, no. 21, p. 5911, 2019.

[23] N. M. Modak, D. K. Ghosh, S. Panda, and S. S. Sana, "Managing green house gas emission cost and pricing policies in a two-echelon supply chain," CIRP Journal of Manufacturing Science and Technology, vol. 20, pp. 1-11, 2018.

[24] P.-K. Chen, F.-D. Chou, X. Dai, and Y. Ye, "Development of a supply chain integration process," IEEE Access, vol. 6, pp. 40226-40244, 2018.

[25] J. Su, C. Li, Q. Zeng, J. Yang, and J. Zhang, "A green closedloop supply chain coordination mechanism based on thirdparty recycling," Sustainability, vol. 11, no. 19, p. 5335, 2019.

[26] N. M. Modak, S. Panda, and S. S. Sana, "Managing a twoechelon supply chain with price, warranty and quality dependent demand," Cogent Business \& Management, vol. 2, no. 1, Article ID 1011014, 2015.

[27] Y. Zhou and S. Wang, "Coordination models of cooperative advertising under stochastic demand in a one-manufacturer two-retailer supply chain system," Journal of Systems Engineering, vol. 26, no. 2, pp. 203-210, 2011.

[28] B. Li, P. W. Hou, and Q. H. Li, "Cooperative advertising in a dual-channel supply chain with a fairness concern of the manufacturer," IMA Journal of Management Mathematics, vol. 28, no. 2, pp. 259-277, 2015.

[29] X.-X. Zheng, Z. Liu, K. W. Li, J. Huang, and J. Chen, "Cooperative game approaches to coordinating a three-echelon closed-loop supply chain with fairness concerns," International Journal of Production Economics, vol. 212, pp. 92-110, 2019.

[30] T. H. H. A. Wu, "Distributional and peer-induced fairness in supply chain contract design," Production \& Operations Management, vol. 23, no. 2, pp. 161-175, 2014.

[31] E. Katok and V. Pavlov, "Fairness in supply chain contracts: a laboratory study," Journal of Operations Management, vol. 31, no. 3, pp. 129-139, 2013.

[32] J. Tang, B.-Y. Li, K. W. Li, Z. Liu, and J. Huang, "Pricing and warranty decisions in a two-period closed-loop supply chain," International Journal of Production Research, vol. 23, pp. 1-17, 2019.

[33] Y. Zhao, S. Wang, T. C. E. Cheng, X. Yang, and Z. Huang, "Coordination of supply chains by option contracts: a cooperative game theory approach," European Journal of Operational Research, vol. 207, no. 2, pp. 668-675, 2010.
[34] W. Xi, F. Shuang, and J. Ping, "Distributed coordination load shedding of islanded microgrids based on sub-gradient algorithm," IEEE Access, vol. 5, pp. 27879-27886, 2017.

[35] Z. Wu, "Optimal control approach to advertising strategies of a supply chain under consignment contract," IEEE Access, vol. 7, pp. 41454-41462, 2019.

[36] L. Jiang, Y. Guo, J. Su, J. Jian, and Y. He, "Sub-coordination in a competing supply chain with a 3PL provider," IEEE Access, vol. 7, pp. 158148-158159, 2019.

[37] N. M. Modak, S. Panda, R. Mishra, and S. S. Sana, "A threelayer supply chain coordination in socially responsible distribution system," Tékhne, vol. 14, no. 1, pp. 75-87, 2016.

[38] E. Cao, "Coordination of dual-channel supply chains under demand disruptions management decisions," International Journal of Production Research, vol. 52, no. 23, pp. 7114-7131, 2014.

[39] G. P. Cachon and A. G. Kök, "Competing manufacturers in a retail supply chain: on contractual form and coordination," Management Science, vol. 56, no. 3, pp. 571-589, 2010.

[40] Y. Kwark, J. Chen, and S. Raghunathan, "Online product reviews: implications for retailers and competing manufacturers," Information Systems Research, vol. 25, no. 1, pp. 93-110, 2014.

[41] J. Lin, W. Yong, X. Yan et al., "Coordinating a three-stage supply chain with competing manufacturers," Central European Journal of Operations Research, vol. 22, no. 1, pp. 53-72, 2014.

[42] Z. Wu, D. Chen, and L. Feng, "Design of optimal control strategies for a supply chain with competing manufacturers under consignment contract," Systems Science \& Control Engineering, vol. 6, no. 1, pp. 171-179, 2018.

[43] N. M. Modak, S. Panda, and S. S. Sana, "Three-echelon supply chain coordination considering duopolistic retailers with perfect quality products," International Journal of Production Economics, vol. 182, pp. 564-578, 2016. 